\title{
Student Perceptions on Blended/Flipped and Traditional Face-to-Face: A Course Redesign Assessment
}

\author{
Yvonne M. Luna ${ }^{1, *} \&$ Stephanie A. Winters ${ }^{1}$ \\ ${ }^{1}$ Department of Sociology, Northern Arizona University, Flagstaff, Arizona, USA \\ *Correspondence: Department of Sociology, Northern Arizona University, P.O. Box 15300, Flagstaff, AZ 86011, \\ USA. Tel: 1-928-523-6135. E-mail: Yvonne.luna@nau.edu
}

Received: April 25, $2020 \quad$ Accepted: June 16, $2020 \quad$ Online Published: July 14, 2020

doi:10.5430/jct.v9n3p1

URL: https://doi.org/10.5430/jct.v9n3p1

\begin{abstract}
The blended and flipped class is often considered the most student-centered type of learning as it promotes deep and life-long learning. Using qualitative and quantitative data from anonymous surveys completed by students in two different introductory classes, one blended and flipped $(\mathrm{N}=56)$ and the other traditional lecture $(\mathrm{N}=74)$ taught by the first author during the same semester, this study reveals active learning in the blended and flipped class contributes to those students': 1) positive perceptions of usefulness of course material; 2) perceptions of more time spent on their class; and 3) preference for blended and flipped learning. These findings provide for a deeper understanding of the results of an earlier study with these same cohorts where the blended and flipped learning outperformed the traditional face-to-face students on a pre-posttest. It also provides insight into the usefulness of blended learning and can help assuage fears that students are short changed when they don't have face-to-face instruction. This article closes with suggestions for instructors wishing to pursue a flipped and blended classroom model.
\end{abstract}

Keywords: active learning, blended learning, flipped learning, student engagement, student satisfaction, learning outcomes

\section{Introduction}

Blended learning is a gaining more attention in higher education often because of the cost-savings it offers as it reduces demands for space and staff (Gavassa, Benabentos, Kravec, Collins, \& Eddy, 2019). As universities have struggled with enrollment declines due to demographic shifts, the COVID-19 pandemic is likely to produce even more strains on revenue as students decide not to pursue higher education in the near future (Hartocollis, 2020). Although alternative forms of learning like online and blended learning offer cost-savings, some may be concerned that students lose out on the benefits of face-to-face instruction. For blended learning courses, this is more of a concern in the replacement model where in-class time is replaced with online time (Auster, 2016). However, there is mounting evidence that blended courses using flipped learning have multiple benefits including suiting different learning styles (Auster, 2016). Relatedly, flipped learning is also increasingly being implemented as it tends to promote student engagement and satisfaction which has a positive relationship with retention (Fisher, Perényi, \& Birdthistle, 2018).

Although often referred to as "blended learning," it is not so much about learning but rather about how content is delivered, or taught. Blended learning is the mixing of modalities, often online and face-to-face (Bliuc, Goodyear, \& Ellis, 2007) and flipped speaks to the design of the course, where content is learned outside of class and in-class time is devoted to application. When flipped pedagogy, also referred to as reverse or inverse teaching, and blended learning are combined, students learn course content outside of class and online while application of material occurs in class (see for example Bliuc et al., 2007; Fisher, et al., 2018; Garrison \& Kanuka, 2004; Gilboy, Heinerichs, \& Pazzaglia, 2015; Nguyen, Yu, Japutra, \& Chen, 2016). The flipped-classroom is often considered the most student-centered type of learning because it is principled on active learning (Burke \& Fedorek, 2017; O'Flaherty \& Phillips, 2015). Students' learning is often the motivating factor for implementing blended and flipped learning. If other motives such as convenience and cost-savings take precedence, these models can be implemented in ways that do not produce the greatest learning outcomes. In 2014, the first author applied for an internal grant to redesign 
Introductory Sociology into a blended course. Although one of the main objectives of the institution was cost-savings, learning effectiveness was paramount.

In an earlier publication, the authors explored the effectiveness of blended and flipped learning. Student learning outcomes using pre-posttest data were measured and it was concluded students in a blended and flipped learning class (BF) outperformed students in a traditional face-to-face (F2F) class (Luna \& Winters, 2017). At the time of that study, the literature was limited in that there were very few side-by-side comparisons (e.g., same course taught by the same instructor during the same semester) of these two types of classes. The focus for that study was on learning outcomes and, as such, analysis of anonymous surveys asking students' about their perceptions concerning their level of engagement and usefulness of course materials and preference for learning modality had not been conducted. In the present study we extend our previous analysis of the pre-posttest data from the BF versus F2F sections by examining student perceptions of engagement and satisfaction in these two sections.

\section{Material Studied}

\subsection{Studies Using Pre-posttest Data}

While previous studies have used pre-posttests to gauge student learning, examine student satisfaction, and compare learning modalities, it is rare to find a study that integrates all three of these components. This study serves to fill this gap.

Using pre-posttests, Ranieri, Raffaghelli, \& Bruni (2018) introduced game-based student response systems and found learning outcomes improved and students were satisfied with the new active learning strategy, but they did not compare learning modalities. Likewise, Demirbilek \& Talan (2018) and Foldnes (2016) used pre-posttests to examine the effectiveness of active learning strategies during lecture-based and flipped learning courses, respectively, but neither compared learning modality. Similarly, Styers, Van Zandt, \& Hayden (2018) used pre-posttests to study the development of critical thinking skills by introducing web-based videos to flip parts of life science courses. Again, comparison across learning modalities was not done nor were student perceptions of the course gathered. On the other hand, Singla, Saini, \& Kaur (2016) used a pre-posttest to make a comparative assessment of flipped and lecture courses amongst nursing students and found that the flipped learning students outperformed lecture students. However, they did not look at student perceptions or satisfaction. Goh \& Ong (2019) used grades as the basis of their pre-posttest with pharmacology students to test learning outcomes in lecture and flipped classrooms. They found students' grades on the final exam in the flipped class were higher than for the lecture students and those students responded positively to the flipped instruction. However, they looked only at satisfaction and did not test student perceptions about their engagement and whether they found the course materials useful.

\subsection{Student Engagement and Satisfaction}

Studies suggest students are more engaged in learner-centered environments than in teacher-centered classrooms as they require active learning as opposed to passive learning (Burke \& Fedorek, 2017; Talley \& Scherer, 2013). It is argued these types of learning environments yield greater academic success (Fisher et al., 2018; Hibbard, Sung, \& Wells, 2016; Peterson, 2016; Prescott et al., 2016). Although traditional lecture courses may employ active learning (Foldnes, 2016), the flipped class presents perhaps the most student-centered pedagogical model and as Akçayir \& Akçayir (2018) point out in their large-scale content analysis of the literature on flipped classrooms, the most cited advantage of flipped learning is improved student performance. This finding corresponds with the results of our previous study as well as those of Ellis, 2016, Harjoto, 2017, Peterson, 2016, and Prescott et al., 2016 that also conclude flipped and/or blended classes improve learning.

Akçayir \& Akçayir (2018) could not conclude, in their meta-analysis of 71 studies, the benefits of flipped learning were due to active learning. However, a few of the studies they analyzed determined that flipped classes enhance engagement and have other benefits such as increased retention, satisfaction, and motivation. This corresponds with the results of a content analysis of twenty studies on flipped instruction concluding that it has positive implications including student motivation and engagement (Zainuddin \& Halili, 2016). Student engagement often refers to the amount of time, resources, and energy exerted toward learning (Exeter, et al., 2010 as cited in Holmes, 2018). Similar to some of the studies in Akçayir \& Akçayir's (2018) assessment, Fisher et al. (2018) found blended and flipped learning contribute to students' perceptions of engagement, performance, and satisfaction. Specifically, they argue well-flipped classes are inherently engaging which can lead to improved performance and satisfaction, although they did not make comparisons to other types of learning models and their study was limited to perceptions of performance. Likewise, Burke \& Fedorek (2017) hypothesized students in a flipped class would score higher on 
self-reported engagement but they actually scored lower as compared to lecture and online students in upper division crime control classes. However, they argue their participants were largely seniors who may have a longer history with and thus preference for passive learning. They note a barrier to the success of flipped learning is dependence on student agency to complete the work prior to class. Holmes (2018) argues integrating assessment into the virtual learning environment encourages engagement and therefore contributes to a positive experience.

Other studies actually calculate students' workload requirements. For example, Phillips, Schumacher, \& Arif (2016) found the actual time pharmaceutical students spent on their blended learning class was similar to that allocated by the instructor but without improvements in learning outcomes. However, they did not make comparisons to other learning environments. Boevé, et al. (2017) explored introductory students' study behavior (e.g., reading, completing homework and practice questions) in flipped and traditional statistics courses and found little difference between the two groups with little impact on student performance. However, ten percent of the studies analyzed by Akçayir \& Akçayir (2018) reported that students in flipped classes spent more time as compared to traditional courses. Comparisons by class standing were not reported. From this literature, it is evident engagement is a key component to academic success and as Ellis (2016) points out, an important variable -- positive perceptions -- can lead to greater student learning.

The literature generally suggests student satisfaction is higher with blended and/or flipped courses than traditional modalities. Some studies examine students' experiences and perceptions, but do not make associations with learning outcomes. In Ellis's (2016) study involving 103 first-year undergraduates, students engaged in online research to complement in-class work. He suggests that the quality of the student experience is shaped by deep learning, an integration of technology, a perception that the workload is not overwhelming and a perception that the in-class and out-of-class activities were linked. He did not, however, link student experiences to learning outcomes. Likewise, in Gilboy et al.'s (2015) study, their students were enrolled in flipped and traditional nutrition courses and a majority of them had a preference for flipped learning over face-to-face although this was not connected to performance. In addition to other lower-level learning, students listened to digitized lectures before class. Similarly, Nguyen et al. (2016) sought to provide a description of students' perceptions of flipped/reverse teaching toward the end of a teaching module. Through interviews with 28 marketing students they found this type of teaching as effective and acknowledge it was limited to only part of a class with advanced marketing students and their findings were not correlated with learning outcomes. A few studies actually link satisfaction to student success.

Hibbard et al.'s, (2016) study of flipped and traditional courses involving general chemistry students at a historically black college and university indicates students' positive perceptions of flipped learning were shaped by how well the online component of the course helped them prepare for assessments. In addition, flipped learning improved performance on standardized exams. Likewise, in Peterson's (2016) research with flipped and traditional statistics courses, he found students in the flipped class outperformed lecture students by one letter grade on the final exam and they were generally more satisfied. Elmer, Carter, Armga, \& Carter (2016) constructed a blinded experimental design to test student performance and perceptions in blended and traditional exercise physiology laboratories and found the blended class did not have improved performance, but students perceived the format as valuable and they were generally more engaged. And for Phillips et al. (2016) in their study involving 427 pharmaceutical students, they found their students were satisfied with blended learning because they were able to use online lectures at their own pace, there were opportunities for application, and it fit different learning styles. Although tested, they did not find these results led to increased learning outcomes. Effectiveness of course design may lie not only in learning outcomes but also positive student perceptions.

\section{Research Question}

Much of the literature on blended and/or flipped learning indicates their effectiveness in terms of student engagement, motivation, satisfaction, and academic performance. The aim of this study is to further understand what contributes to deep learning by examining two different Introductory Sociology classes -- one blended and flipped (BF) and the other traditional face-to-face (F2F), both with active learning elements, albeit to differing degrees, and offer insights into why BF courses may be more beneficial than F2F courses for introductory students. In our earlier study, although there were no significant differences in final grades between these same two groups, students in the blended/flipped class had significantly greater improvement on an overall pre-posttest. In order to explain those findings, a deeper analysis is warranted. In this current study, quantitative and qualitative data from anonymous surveys is measured and compared across the two sections by assessing students' perceptions of usefulness of course materials and time spent on class together with their preference for learning modality and suggestions for improving 
the course.

\section{Method}

Data for this study comes from student responses to an anonymous survey conducted in two different sections of Introductory Sociology taught by the first author in the fall 2014 semester at a public university in the US southwest enrolling over 21,000 full-time resident students that year (Northern Arizona University, 2020). One section was blended (i.e., two-thirds of the class involved face-to-face meetings and one-third included out-of-class activities) using flipped pedagogy (BF) and the other was taught in a traditional face-to-face (F2F) format. This is a quasi-experimental design in that students were not randomly assigned to the blended or traditional face-to-face sections. In fact, only 7-percent of the blended students said they enrolled in that class because of the format. Most selected it because the meeting time worked well with their schedules.

\subsection{Structure of Courses}

The BF and F2F Introductory Sociology classes included the same quantity and quality of online quizzes and exams, out-of-class assignments, and attendance was counted toward final grades for all in-person sessions. The eleven online quizzes were open for one week each, administered through the learning management system, Blackboard Learn, consisting of ten multiple-choice questions, with unlimited attempts and the last attempt score being the final mark. Each of the three exams were also online, fifty questions, and students had only one attempt and 70 minutes to complete them. The out-of-class (e.g., homework) assignments were made available online after students had opportunities to learn the sociological content and required them to read an assigned article and apply course content to an analysis of it by answering two to four essay questions. For example, for the section on social structure and social interaction, students read an article about human behavior in public bathrooms (Cahill et al., 2001). The questions were centered on the application of Goffman's dramaturgical model to behaviors described in the article. In addition, they had to describe ways in which they engage in impression management in their own lives and how it relates to dramaturgy. Despite the many similarities in course requirements, the classes diverged in important ways.

The differences between the classes were centered on four key elements. First, the F2F students had more in-person class time (150 versus 100 minutes) and discussion-based lecture comprised a majority of that time. Second, the BF students completed nine online learning assignments designed by the textbook publisher for each topic focused on comprehension of course content. The assignments were animated often with both voice and video imaging requiring students to respond to anywhere from three to ten questions by writing a few words or selecting responses to multiple-choice or true/false questions. Each assignment was available for one week and students had three attempts with their highest score being the final mark for each. Third, in the BF class, the instructor's lecture was also discussion-based but strategically planned by assessing responses to the online quizzes and learning assignments to determine which content was most difficult for the students. Finally, more class time was devoted to application exercises in the BF section. Specifically, the F2F students completed a third of the in-class application exercises as compared to the BF students. The application exercises consisted of collaborative learning with four to six students, where they grappled with questions, and wrote one group answer with each student earning the same grade. It's important to note that not all assignments were graded. For example, for the section on social structure and social interaction, the instructor played a four-minute video about working mothers. After viewing the video and breaking into groups, students discussed and answered three questions: describe the role conflict presented in the video; what are two other examples of role conflict?; what are some possible consequences of living with long-term role conflict? Before class ended, the entire class convened and groups shared their answers while the instructor facilitated a discussion, and each group submitted their completed worksheet with each student's name listed. In order to capture students' perceptions of their courses, an anonymous survey was administered mid-way through the semester.

\subsection{Survey Instrument}

The anonymous mid-term survey was adapted from a tool developed to measure student experiences in flipped and lecture format courses in fundamental microbiology (Adams, Randall, \& Traustadóttir, 2014). The survey consisted of seven close-ended questions asking students to rank their opinion of the usefulness of course-related materials such as the textbook and in-and out-of-class activities. Items were ranked along a five-point Likert scale ranging from not at all to very. Additionally, students were asked to indicate whether time requirements and the effectiveness of their course format was more, less, or no different than other classes they were taking or had taken at the university. Our results below do not include perceptions of course format effectiveness since our earlier study reported actual differences in learning outcomes between formats. Students were also asked to rank a series of statements concerning their interest in sociology on a 5-point Likert scale from not at all to very. There were no significant differences in 
these outcomes so these data are therefore not reported below. Finally, students in both classes were given the opportunity to convey, in their own words, one thing they would change about the course. Students in the BF class were given additional questions asking about specific aspects of their course format, including their preference for blended learning or traditional lecture format courses and the usefulness of the online learning assignments.

Validity of the questionnaire items were assessed in an upper division social statistics class prior to participant completion. The 28 students in the statistics class had previously practiced evaluating survey items for validity through various statistical exercises and applications. They were therefore assumed to possess adequate faculties to judge and critique the effectiveness and clarity of the survey instrument. Students provided feedback on clarity of question wording which was incorporated in the final version of the survey distributed to the Introductory Sociology classes. It was administered during mid-term at the beginning of one in-person class period and responses were gathered immediately upon completion. No identifying or demographic information was ascertained other than self-reported class standing. Therefore, responses could not be linked to individual students or to other data collected including pre-posttest scores and grades. Students had the option to complete the survey and a total of $87 \%$ of the lecture and $84 \%$ of the blended students did so as represented in Table 1.

Table 1. Mid-term Anonymous Survey Participants

\begin{tabular}{llllll}
\hline & \multicolumn{2}{l}{ Face-to-Face } & \multicolumn{2}{l}{ Blended/Flipped } & \multirow{2}{*}{ p-value } \\
\cline { 2 - 5 } & $\mathrm{N}$ & $\%$ & $\mathrm{~N}$ & $\%$ & .200 \\
\hline First Year & 25 & 34 & 36 & 64 & .001 \\
Non-First Year & 49 & 66 & 20 & 36 & - --- $^{2}$ \\
Total $(\mathrm{N}=130)$ & 74 & 87 & 56 & 88 & \\
\hline
\end{tabular}

Difference of proportions tests were conducted to determine if the number of first-year and non-first year students across sections was significantly different. Tests revealed the proportion of non-first year students in the F2F section was significantly greater than those in the BF class. Therefore, significant differences in student satisfaction for that group are not reported here.

Although most of the information is presented in aggregate, pseudonyms are used to express qualitative comments. In an earlier study with these same groups of students, those in the BF class outperformed students in the F2F class on a pre- to posttest. Their perceptions of engagement with the course and preference for learning modality are explored here. In 2014, blended and flipped learning were concepts relatively new to students at this university. Accordingly, the mid-term anonymous survey was constructed around the assumption that students were primarily enrolled in traditional lecture classes and fewer, if any, blended classes. Finally, this study was approved by the University's Institutional Review Board and students 18-years of age and older signed informed consent forms and students 17-years of age signed minor assent forms with their legal guardians providing written consent.

\section{Results}

\subsection{Usefulness of Out-of-class Activities}

Students in both classes were required to read, take quizzes about the readings, and do assignments outside of class (i.e., homework). There were no significant differences between the blended and flipped learning (BF) and traditional face-to-face (F2F) students in their perceptions of usefulness of the online reading quizzes. However, there were significant differences between the BF and F2F students in their perceptions of the usefulness of the textbook and homework assignments, with the BF students finding them more useful than did the F2F students as indicated in Table 2. 
Table 2. Satisfaction/Usefulness of Course Materials

\begin{tabular}{|c|c|c|c|c|c|c|c|c|c|c|c|c|}
\hline & \multicolumn{2}{|l|}{ Overall } & \multirow[t]{3}{*}{$\mathrm{t}$} & \multirow[t]{3}{*}{$\mathrm{p}$} & \multicolumn{2}{|c|}{$\begin{array}{l}\text { First-Year } \\
\text { Students }\end{array}$} & \multirow[t]{3}{*}{$\mathrm{t}$} & \multirow[t]{3}{*}{$\mathrm{p}$} & $\begin{array}{l}\text { Non-First } \\
\text { Students }\end{array}$ & Year & \multirow[t]{3}{*}{$\mathrm{t}$} & \multirow[t]{3}{*}{$\mathrm{p}$} \\
\hline & $\begin{array}{l}\mathrm{F} 2 \mathrm{~F} \\
(\mathrm{~N}=74)\end{array}$ & $\begin{array}{l}\mathrm{BF} \\
(\mathrm{N}=56)\end{array}$ & & & $\begin{array}{l}\mathrm{F} 2 \mathrm{~F} \\
(\mathrm{~N}=25)\end{array}$ & $\begin{array}{l}\mathrm{BF} \\
(\mathrm{N}=36)\end{array}$ & & & $\begin{array}{l}\mathrm{F} 2 \mathrm{~F} \\
(\mathrm{~N}=25)\end{array}$ & $\begin{array}{l}\mathrm{BF} \\
(\mathrm{N}=36)\end{array}$ & & \\
\hline & Mean & Mean & & & Mean & Mean & & & Mean & Mean & & \\
\hline Usefulness of Textbook & 3.28 & 3.91 & -3.231 & $.002 *$ & 3.40 & 3.94 & -1.921 & .060 & 3.23 & 3.84 & -2.013 & .052 \\
\hline $\begin{array}{l}\text { Usefulness of Weekly } \\
\text { Readings Quizzes }\end{array}$ & 3.85 & 3.79 & .398 & .691 & 4.12 & 3.81 & 1.215 & .229 & 3.69 & 3.74 & -.232 & .818 \\
\hline $\begin{array}{l}\text { Usefulness of Homework } \\
\text { Assignments }\end{array}$ & 3.18 & 3.71 & -2.834 & $.005^{*}$ & 3.12 & 3.81 & -2.347 & $.022 *$ & 3.21 & 3.58 & -1.407 & .167 \\
\hline
\end{tabular}

*Statistically significant difference at the $\mathrm{p}<0.05$ level.

Although there were no statistically significant differences between first year and non-first year students across the two sections, a combination of those data make for significant differences overall.

\subsection{Time Spent on Class}

Results from the anonymous midterm survey revealed $25 \%$ of the students in the blended and flipped (BF) class believed they spent more time on their class as compared to other classes they had taken at this school while only $7 \%$ of those in the face-to-face (F2F) class said they spent more time. Conversely, $18 \%$ believed they spent less time on their blended sociology course and $45 \%$ of the lecture students responded they spent less time as represented in Table 3.

Table 3. Engagement/time Spent on Class

\begin{tabular}{lllllll}
\hline \multirow{2}{*}{ Category } & \multicolumn{2}{l}{ Overall (\%) } & \multicolumn{2}{l}{ First-Year (\%) } & \multicolumn{2}{l}{ Non First-Year (\%) } \\
\cline { 2 - 7 } & F2F & BF & F2F & BF & F2F & BF \\
\hline Less & 45 & 18 & 32 & 11 & 51 & 30 \\
Same amount & 49 & 57 & 52 & 61 & 47 & 50 \\
More & 7 & 25 & 16 & 28 & 2 & 20 \\
\hline
\end{tabular}

These responses reveal BF students perceived a greater time commitment compared to their counterparts in the F2F course. The patterns remained constant for first year and non-first year students.

\subsection{Students' Preferred Course Format}

Students in the BF class were asked "If given a choice in course format, which do you prefer? Blended learning, online, lecture, or no preference." F2F students were not asked this question as it was not assumed they had experience with blended classes. Overall, 29 of them or 52\% said they prefer blended learning. Of those, ten said they like independent learning. For example, Jenny wrote "It allows me to learn alone and take more time on it." Six students said they like a mixture of learning modalities, like Adam who wrote "This style course provides a great combination between traditional lecture-style learning and independent learning." Four said they like applying the material. Bernice said, "Being able to discuss what you've read in class is an easier way of understanding material."

Although blended learning was preferred by the majority, 14 students or $25 \%$ of the BF students said they prefer lecture classes. Seven of them indicated they like learning from the professor and/or note-taking. Mabel wrote "I tend to learn better from listening and reading rather than applying and doing group work." The remainder of those who said they prefer lecture said they do not like independent or online learning. David commented "It tends to happen in blended classes that the lectures are very short or nonexistent, so I have to teach myself the material." The remaining students in the BF class did not answer the question or had no preference as demonstrated in Table 4. 
Table 4. Percentage of Blended Students' Learning Preference

\begin{tabular}{lccc}
\hline \multirow{2}{*}{ Preference } & Overall (\%) & First-Year (\%) & Non First-Year (\%) \\
& $\mathrm{N}=56$ & $\mathrm{~N}=36$ & $\mathrm{~N}=48$ \\
\hline Blended & 52 & 44 & 65 \\
Lecture & 25 & 33 & 10 \\
Online & 2 & 3 & 0 \\
No Preference & 20 & 17 & 25 \\
Missing & 2 & 3 & 0 \\
\hline
\end{tabular}

When analyzing responses by academic level, $44 \%$ of the 36 first year students preferred blended learning while $33 \%$ preferred lecture. Most of those who answered they prefer blended said they like autonomous learning. For example, Holly said "It allows us to be more independent, but we can also seek help/review in class to confirm that we are learning the material." Other first year students who prefer blended learning said they like the combination learning. Maria said "I like the blended format because it allows for both lecture and online work. The actual class is not as time consuming and it allows me to work on my own time outside of class." Yet, some said they like applying the material. Jeff wrote "I like that we come to class somewhat understanding the concepts and [professor] makes them clear and applies them to real situations. This is so helpful to me in understanding this course!" Conversely, many of the first-year students in the blended class who said they prefer lecture wrote they enjoy learning from the professor, like John who said, "I learn best when the teacher explains things and gives examples."

Likewise, a majority ( $65 \%$ of 20 ) of the non-first year students in the blended class clearly had a preference for blended learning. They said they liked independent learning and the combination of online and face-to-face learning. Only two non-first year students said they preferred lecture.

\subsection{Students' Suggestions for Improving the Course}

Students in both classes were asked an open-ended question, "If you could change one thing about this course, what would it be?" Responses were analyzed qualitatively for key themes. Some students indicated that no changes were needed, or they weren't sure. For the remaining, the following themes emerged: more in-class time or lecture, fewer or no homework assignments, less in-class time, and more opportunities to apply the course material. These categories are represented quantitatively in Table 5.

Table 5. Suggestions for Improving the Course

\begin{tabular}{lcccccc}
\hline \multirow{2}{*}{ Category } & Overall (\%) & \multicolumn{3}{c}{ First-Year (\%) } & \multicolumn{2}{c}{ Non First-Year (\%) } \\
\cline { 2 - 7 } & F2F & BF & F2F & BF & F2F & BF \\
\hline Nothing/ not sure & 32 & 21 & 28 & 22 & 35 & 20 \\
More in-class time/ lecture & 5 & 36 & 8 & 42 & 4 & 25 \\
Do not like homework & 11 & 9 & 12 & 8 & 10 & 15 \\
Less in-class Time/attendance & 7 & 7 & 12 & 6 & 4 & 10 \\
More application of material & 8 & 0 & 4 & 0 & 10 & 0 \\
Other & 15 & 13 & 8 & 11 & 19 & 15 \\
No response & 22 & 14 & 28 & 11 & 19 & 15 \\
\hline
\end{tabular}

An analysis of the qualitative data by academic class standing and learning modality reveals that the blended/flipped (BF) students clearly wanted more in-class time/lecture (36\% overall, $42 \%$ of the first-year students and $25 \%$ of the non-first year students). Steve commented, "I would make the lectures a little longer. I feel that sometimes we do not have enough time for instruction or activities." Another student, Alyssa wrote "Not having the homework applying the class to me. Rather have the teacher apply it to me." Alyssa's response implies she prefers when the instructor explains the material rather than learning it independently. Only 8-percent of the first-year students and 4-percent of the non-first year students in the face-to-face (F2F) class indicated they wanted more in-class time or lecture.

Other interesting findings were that a greater percentage of F2F students as compared to BF students suggested fewer or no homework assignments. Ursula said, "The homework assignments seem pointless to me and irrelevant." The non-first year students in the BF class also wanted more in-class time/lecture, but their responses indicate a preference for less application and group work and therefore more lecture. Jose said, "More in class lecture, less group time." Finally, only the F2F students indicated inadequate opportunities to apply the course materials. Mary commented, "I don't feel like I apply the information I learn." Similarly, Angel wrote, "I would create a group 
project at the end of this course so that students could interact more with one another."

In summary, students' responses to our anonymous midterm course survey revealed the following overall patterns: $\mathrm{BF}$ students perceived the readings and homework assignments as more useful; BF students remarked they spend more time on their class, whereas more F2F students spend less time; BF students prefer blended, but they suggest more in-class time/lecture; and F2F students want more opportunities for application of course material. These patterns held true when comparing first year and non-first year students in the BF class with those same cohorts in the F2F class. Suggestions about how to incorporate these elements into a BF class are offered in the discussion and conclusion.

\section{Discussion and Conclusion}

In an earlier study analyzing data from these same groups of students, the authors found the blended and flipped learning (BF) students outperformed the traditional face-to-face (F2F) students on an overall pre-posttest $(\mathrm{t}=-2.03, \mathrm{p}$ $=.04)$ as did non-first year students in that class compared to that same subgroup in the lecture class $(\mathrm{t}=-4.25, \mathrm{p}=.00)$ (Luna \& Winters, 2017)). This current analysis reveals blended and flipped learning contributes to students' positive perceptions of the usefulness of course material, greater demand for their time toward learning the course material, and their preference for blended and flipped learning. Specifically, significantly more students in the BF section of Introductory Sociology as compared to students in the F2F class found the textbook and homework assignments useful. The online learning exercises required them to read and/or refer to the textbook in order to adequately answer questions that were graded. As Holmes (2018) points out, students tend to seriously engage course material when it is assessed and marked. Additionally, since they were grappling with the course content through the readings and the online learning assignments, students may have found they were able to complete the application homework assignments much more easily, thus useful, than students in the lecture class. In fact, some of the lecture students said the homework had little value. Correspondingly, it makes sense that larger percentages of the BF students believe their class required more of a time commitment as compared to their other classes, a finding consistent with 10-percent of the studies analyzed by Akçayir \& Akçayir (2018). This is a meaningful contrast with the F2F students who nearly half said their class required less time. Furthermore, these results were consistent by class standing. Thus, we suggest replacing class time with highly structured and rigorous online time so that students remain engaged.

Although the course required more of their time, albeit less in-person class time, a great majority of non-first year students and just less than half of the first-year students in the BF class said they preferred the blended learning format. As the qualitative comments demonstrate, students liked independent learning, the mixture of online and in-person, and applying the material. It's possible that time efficiency and the convenience of completing coursework at their own pace influence perceptions of satisfaction (Fisher et al., 2018; Phillips et al., 2016) and performance (Gavassa et al., 2019). Additionally, students in the BF class said they found the readings and homework useful. It is likely the course structure forced them to spend time engaging the materials, which influenced their perceptions of their usefulness and their preference for blended learning. As Gavassa et al.'s (2019) study shows, schedule flexibility is important, but flipped courses that are highly structured produce higher learning outcomes as compared to online and lecture courses, especially for students of color, a finding consistent with our earlier study. We suggest tying assessment to reading assignments so students are motivated to read the course material and structuring both online and in-person portions of the course with application exercises.

Interestingly, over $40 \%$ of the first-year students and $25 \%$ of the non-first year students in the BF class said they would like more in-class time and lecture. This finding complements Van Alten, Phielix, Janssen, \& Kester (2019) who argue flipped classes that do not reduce class time are more effective. The qualitative comments from first year students provide some context as many of them said they prefer learning from the professor. Related to this, nearly half of all the F2F students and a third of the first-year students in that class said they spent less time on their Introductory Sociology lecture course as compared to their other courses. Conceivably first year students favor passive or "teacher-centered" learning (Weimer, 2002) that requires less effort and time (Roehling, Lindsey, Luna, Fallon, \& Shaugnessy, 2017) and where the teacher is a sage rather than guide (McLean \& Attardi, 2018). For the non-first year students in the BF class, their comments suggest they desired less interaction with other students, thus more lecture, possibly because their classmates were likely first year students. Or, perhaps as Umek, Tomaževič, Aristovnil, \& Keržič (2017) note, the organization of the online components of blended learning play a less significant role for students in higher academic levels.

This study supports the case for consistency in course format that requires high levels of student engagement such as in blended, flipped courses centered on active learning. When students take classes requiring engagement and active 
participation and are able to make comparisons to other courses where they can be passive, they may be resistant to high expectations. Tinto (2012) contends that setting expectations results in students putting forth effort and adapting behaviors necessary for success and leading to achievement. One way in which faculty can accomplish this is through pedagogical strategies requiring high levels of student effort, but this expectation must be constantly reinforced within individual courses and within programs of study. In addition, evidence suggests that flipped learning, more so than lecture, promotes higher order thinking and engagement (Roehling, 2018). We suggest that for programs with several sections of introductory courses that they be consistent in course format, learning outcomes, rigor, and expectations.

This research complements Roehling et al.'s (2017) findings which suggest that students in flipped social science classes like the flipped format and also value lecture, a sentiment particularly true for first year students. In addition to consistency in rigor and expectations -- characteristics inherent in flipped and active learning classes -- lecture designed purposefully based on assessment of student understanding of the course material can enhance the flipped experience. Rather than completely doing away with lecture, the BF Introduction to Sociology classes at this particular institution are structured in a way where the instructor assesses student comprehension of course material prior to class so that in-class time is devoted to lecture centered on difficult content before students move on to application. In addition, and in contrast to Van Alten et al. (2019), these findings suggest that reduced face-to-face time in flipped classes is not detrimental to learning, suggesting that reductions in in-class time benefit the institution in terms of cost-savings but can also benefit students when instructors focus on material most difficult for them. However, this study did not include comparison of flipped classes with differing degrees of in-class time. As the Introductory Sociology course structure shifts to less in-person class time, our future research aims to better understand the implications of the amount of class time in flipped classes.

\section{Limitations and Future Research}

There are limitations to this study. Students were not asked for demographic data in the mid-term survey such as sex, race, or major discipline. They were asked only for class standing which limited the ability of the researchers to link survey responses to known sub-populations. This would have been particularly valuable given that students of color in the BF class outperformed that subgroup of students in the F2F course (Luna \& Winters, 2017). Additionally, students were not randomly assigned to the classes and this may have limited the internal validity of the study. Similarly, assessing student's familiarity with blended or online learning prior to taking these classes would have provided for a better understanding of their performance and preference for learning modality. Finally, this study uses perceptions of usefulness of course material and time spent on class. Actual measurements of these variables could produce different results. For example, we recommend asking students to keep a log of their time spent on the course.

The great depth of scholarship on teaching and learning is proof that many teachers are critically examining learning. This is especially important as institutions of higher education face unique challenges brought by the COVID-19 pandemic. Our unique methodological approach utilizing quantitative and qualitative data, comparing two types of learning modalities over an entire semester provides a strong basis for our conclusions. Given the positive results for blended and flipped learning, we agree with McNally, et al. (2017) that entire courses should be flipped and blended. Second, consistent with Gavassa et al., (2019) and Holmes (2018), the out-of-class portion of blended and flipped courses should be engaging and assessed such that it forces students to read course material while also keeping them interested. As such, video lectures are not recommended as they tend toward passivity and boredom (Gilboy et al., 2015). Out-of-class assignments should provide the instructor with a mechanism to assess student understanding of the material so that they can purposefully design the in-class portion, especially short-structured lectures followed by active learning exercises. Lectures and homework should be designed to connect and reinforce one another. Consistent with Jensen, Kummer, \& Godoy (2015), active learning in the classroom is a critical component of the flipped class and it is perhaps most influential in producing positive learning outcomes. We also endorse using the same few active learning strategies in and out of class (Gilboy et al., 2015). The structure and types of our assignments remained consistent throughout the semester. Finally, we suggest blended and flipped courses be structured in a way such that students are learning content outside of class, class time is used for short lectures and active learning, followed by additional out-of-class application work.

\section{Acknowledgments}

The authors acknowledge the students who participated in this study. Our hope is they are enjoying fruitful careers. 
We would also like to thank Northern Arizona University's President's Technology Initiative grant for supporting the redesign of Introduction to Sociology and making this study possible. Additionally, we extend our gratitude to our readers, Drs. Phoebe Morgan, Lori Poloni-Staudinger, and Alison Adams. And finally, we sincerely appreciate the hard work of Graduate Assistant, Emilia Ravetta, for her help in locating articles, formatting citations, and overall assistance with the finite requirements of publication.

\section{Funding}

The study was supported by an internal institutional course redesign and assessment grant. The authors received no financial support for the authorship or publication of this article.

\section{References}

Adams, A. E., Randall, S., \& Traustadóttir, T. (2014). A tale of two sections: An experiment to compare the effectiveness of hybrid versus a traditional lecture format in Introductory Microbiology. CBE-Life Sciences Education, 14(1), 1-8. https://doi.org/10.1187/cbe.14-08-0118

Akçayır, G., \& Akçayır, M. (2018). The flipped classroom: A review of its advantages and challenges. Computers and Education, 126(1), 334-345. https://doi.org/10.1016/j.compedu.2018.07.021

Auster, C. J. (2016). Blended learning as a potentially winning combination of face-to-face and online learning. Teaching Sociology, 44(1), 39-48. https://doi.org/10.1177/0092055X15619217

Bliuc, A. M., Goodyear, P., \& Ellis, R. A. (2007). Research focus and methodological choices in studies into students' experiences of blended learning in higher education. The Internet and Higher Education, 10(4), 231-244.

Boevé, A., Meijer, R., Bosker, R., Vugteveen, J., Hoekstra, R., \& Albers, C. (2017). Implementing the flipped classroom: An exploration of study behavior and student performance. Higher Education, 74(6), 1015-1032. https://doi.org/10.1007/s10734-016-0104-y

Burke, A., \& Fedorek, B. (2017). Does "flipping" promote engagement? A comparison of a traditional, online, and flipped class. Active Learning in Higher Education, 18(1), 11-24. https://doi.org/10.1177/1469787417693487

Cahill, S. E., Distler, W., Lachowetz, C., Meaney, A., Tarallo, R., \& Willard, T. (2001). Meanwhile backstage: Behavior in public bathrooms. Sociological Odyssey: Contemporary Readings in Sociology, 132-142.

Demirbilek, M., \& Talan, T. (2018). The effect of social media multitasking on classroom performance. Active Learning in Higher Education, 19(2), 117-129. https://doi.org/10.1177/1469787417721382

Ellis, R. A. (2016). Qualitatively different university student experiences of inquiry: Associations among approaches to inquiry, technologies and perceptions of the learning environment. Active Learning in Higher Education, 17(1), 13-23. https://doi.org/10.1177/1469787415616721

Elmer, S. J., Carter, K. R., Armga, A. J., \& Carter, J. R. (2016). Blended learning within an undergraduate exercise physiology laboratory. Advances in Physiology Education, 40(1), 64-69. https://doi.org/10.1152/advan.00144.2015

Exeter, D. J., Ameratunga, S., Ratima, M., Morton, S., Dickson, M., Hsu, D., \& Jackson, R. (2010). Student engagement in very large classes: The teachers' perspective. Studies in Higher Education, 35(7), 761-775. https://doi.org/10.1080/03075070903545058

Fisher, R., Perényi, A., \& Birdthistle, N. (2018). The positive relationship between flipped and blended learning and student engagement, performance and satisfaction. Active Learning in Higher Education, 1-17. https://doi.org/10.1177/1469787418801702

Foldnes, N. (2016). The flipped classroom and cooperative learning: Evidence from a randomized experiment. Active Learning in Higher Education, 17(1), 39-49. https://doi.org/10.1177/1469787415616726

Garrison, D. R., \& Kanuka, H. (2004). Blended learning: Uncovering its transformative potential in higher education. The Internet and Higher Education, 7(2), 95-105. https://doi.org/10.1016/j.iheduc.2004.02.001

Gavassa, S., Benabentos, R., Kravec, M., Collins, T., \& Eddy, S. (2019). Closing the achievement gap in a large introductory course by balancing reduced in-person contact with increased course structure. CBE Life Sciences Education, 18(8), 1-10. https://doi.org/10.1187/cbe.18-08-0153

Gilboy, M. B., Heinerichs, S., \& Pazzaglia, G. (2015). Enhancing student engagement using the flipped classroom. 
Journal of Nutrition Education and Behavior, 47(1), 109-114. https://doi.org/10.1016/j.jneb.2014.08.008

Goh, C. F., \& Ong, E. T. (2019). Flipped classroom as an effective approach in enhancing student learning of a pharmacy course with a historically low student pass rate. Currents in Pharmacy Teaching and Learning, 11(6), 621-629. https://doi.org/10.1016/j.cptl.2019.02.025

Harjoto, M. A. (2017). Blended versus face-to-face: Evidence from a graduate corporate finance class. Journal of Education for Business, 92(3), 129-137. https://doi.org/10.1080/08832323.2017.1299082

Hartocollis, A. (2020, April 15). After coronavirus, colleges worry: Will students come back? New York Times. Retrieved from https://www.nytimes.com/2020/04/15/us/coronavirus-colleges-universities-admissions.html?campaign_id=9\&e $\mathrm{mc}=$ edit_NN_p_20200415\&instance_id $=17652 \& n l=$ morning-briefing\&regi_id $=101158460 \&$ section=topNews \&segment_id $=25205 \&$ te $=1 \&$ user_id $=2$ beb4d6697a63bcba3ec823f53a0d24a

Hibbard, L., Sung, S., \& Wells, B. (2016). Examining the effectiveness of a semi-self-paced flipped learning format in a college general chemistry sequence. Journal of Chemical Education, 93(1), 24-30. https://doi.org/10.1021/acs.jchemed.5b00592

Holmes, N. (2018). Engaging with assessment: Increasing student engagement through continuous assessment. Active Learning in Higher Education, 19(1), 23-34. https://doi.org/10.1177/1469787417723230

Jensen, J. L., Kummer, T. A., \& Godoy, P. D. d M. (2015). Improvements from a flipped classroom may simply be the fruits of active learning. CBE-Life Sciences, 14(1), 1-12. https://doi.org/10.1187/cbe.14-08-0129

Luna, Y. M., \& Winters, S. A. (2017). Why did you blend my learning? A comparison of student success in lecture and blended learning Introduction to Sociology courses. Teaching Sociology, 45(2), 116-130. https://doi.org/10.1177/0092055X16685373

McLean, S., \& Attardi, S. M. (2018). Sage or guide? Student perception of the role of instructor in a flipped classroom. Active Learning in Higher Education, 1-13. https://doi.org/10.1177/1469787418793725

McNally, B., Dorsett, P., Del Fabbro, L., Frommolt, V., Goetz, S., Lewohl, J., Molineux, M., Pearson, A., Reddan, G., Roiko, A., \& Rung, A. (2017). Flipped classroom experiences: Student preferences and flip strategy in a higher education context. Higher Education, 73(2), 281-298. https://doi.org/10.1007/s10734-016-0014-z

Nguyen, B., Yu, X., Japutra, A., \& Chen, C. (2016). Reverse teaching: Exploring student perceptions of "flip teaching. Active Learning in Higher Education, 17(1), 51-61. https://doi.org/10.1177/1469787415616727

Northern Arizona University. 2020. 2014 PAIR quick facts. Retrieved from https://in.nau.edu/wp-content/uploads/sites/129/2018/08/Fall2014QF-ek.pdf

O'Flaherty, J., \& Phillips, C. (2015). The use of flipped classrooms in higher education: A scoping review. The Internet and Higher Education, 25, 85-95. https://doi.org/10.1016/j.iheduc.2015.02.002

Peterson, D. J. (2016). The flipped classroom improves student achievement and course satisfaction in a statistics course. Teaching of Psychology, 43(1), 10-15. https://doi.org/10.1177/0098628315620063

Phillips, J. A., Schumacher, C. \& Arif, S. (2016). Time spent, workload, and student and faculty perceptions in a blended learning environment. American Journal of Pharmaceutical Education, 80(6), 1-9.

Prescott, W. A. J., Woodruff, A., Prescott, G. M., Albanese, N., Bernhardi, C., \& Doloresco, F. (2016). Introduction and assessment of a blended-learning model to teach patient assessment in a doctor of pharmacy program. American Journal of Pharmaceutical Education, 80(10), 1-10.

Ranieri, M., Raffaghelli, J. E., \& Bruni, I. (2018). Game-based student response system: Revisiting its potentials and criticalities in large-size classes. Active Learning in Higher Education. https://doi.org/10.1177/1469787418812667

Roehling, P. V., Lindsey, M., Luna, R., Fallon, J. R., \& Shaugnessy, J. J. (2017). The benefits, drawbacks, and challenges of using a flipped classroom in and Introduction to Psychology course. Teaching of Psychology, 44(3), 183-192. https://doi.org/10.1177/0098628317711282

Roehling, P. V. (2018). Flipping the college classroom: An evidence based guide. New York, NY: MacMillan. https://doi.org/10.1007/978-3-319-69392-7

Singla, N., Saini, P., \& Kaur, J. (2016). Evaluating the flipped vs traditional teaching method on student nurse's performance. International Journal of Community Health and Medical Research, 2(4), 30-37. 
Styers, M. L., Van Zandt, P. A., \& Hayden, K. L. (2018). Active learning in flipped life science courses promotes development of critical thinking skills. CBE-Life Sciences Education, 17(3), 1-13. https://doi.org/10.1187/cbe.16-11-0332

Talley, C. P., \& Scherer, S. (2013). The enhanced flipped classroom: Increasing academic performance with student recorded lecturers and practice testing a "flipped" STEM course. The Journal of Negro Education, 82(3), 339-347. https://doi.org/10.7709/jnegroeducation.82.3.0339

Tinto, V. (2012). Completing college: Rethinking institutional action. Chicago, IL: The University of Chicago Press. https://doi.org/10.7208/chicago/9780226804545.001.0001

Umek, L., Tomaževič, N., Aristovnik, A., \& Keržič, D. (2017). Predictors of student performance in a blended-learning environment: An empirical investigation. International Conference on E-Learning, 113-120.

Van Alten, D., Phielix, C., Janssen, J., \& Kester, L. (2019). Effects of flipping the classroom on learning outcomes and satisfaction: A meta-analysis. Educational Research Review, 28, 1-18. https://doi.org/10.1016/j.edurev.2019.05.003

Weimer, M. (2002). Learner-centered teaching: Five key changes to practice. San Francisco: Jossey-Bass.

Zainuddin, Z., \& Halili, S. H. (2016). Flipped classroom research and trends from different fields of study. International Review of Research in Open and Distance Learning, 17(3), 313-340. https://doi.org/10.19173/irrodl.v17i3.2274

\section{Copyrights}

Copyright for this article is retained by the author(s), with first publication rights granted to the journal.

This is an open-access article distributed under the terms and conditions of the Creative Commons Attribution license (http://creativecommons.org/licenses/by/4.0/). 